\title{
Serum concentrations of adiponectin, leptin, resistin, ghrelin and insulin and their association with obesity indices in obese normo- and hypertensive patients - pilot study
}

\author{
Mariusz Stępień ${ }^{1}$, Rafał N. Wlazeł², Marek Paradowski², Maciej Banach³, Magdalena Rysz ${ }^{1}$, \\ Małgorzata Misztal ${ }^{4}$, Jacek Rysz ${ }^{1}$
}

\author{
${ }^{1}$ Department of Nephrology, Hypertension and Family Medicine, WAM University \\ Hospital, Lodz, Poland \\ 2Department of Laboratory Diagnostics and Clinical Biochemistry, Medical University \\ of Lodz, Poland \\ ${ }^{3}$ Department of Hypertension, Medical University of Lodz, Poland \\ ${ }^{4}$ Chair of Statistical Methods, University of Lodz, Poland
}

Submitted: 15 April 2012

Accepted: 11 June 2012

Arch Med Sci 2012; 8, 3: 431-436

DOI: 10.5114/aoms.2012.29397

Copyright (c) 2012 Termedia \& Banach

\section{Abstract}

Introduction: Hypertension often coexists with obesity. Adipokines, ghrelin and insulin play important roles in the pathogenesis of both diseases. The aim of this study was to compare adiponectin, leptin, resistin, insulin and ghrelin mean serum concentrations and insulin resistance (HOMA-IR) in normo- and hypertensive patients with obesity.

Material and methods: All included patients were divided on the following groups: non-diabetic hypertensive patients with class I obesity (group A, $n=21$ ) and class II/III obesity (group B, $n=10$ ), and normotensive obese (class I)patients (group C, $n=7$ ). Correlations between obesity indices (body mass index [BMI], waist-tohip ratio [WHR], waist circumference [WC]), HOMA-IR, and hormone and adipokine serum levels were also analyzed.

Results: Leptin level and HOMA-IR were significantly higher in group B compared to group C $(9.74 \pm 3.88 \mathrm{ng} / \mathrm{ml}$ vs. $4.53 \pm 3.00 \mathrm{ng} / \mathrm{ml} ; p<0.02$ and $3.30 \pm 1.59$ vs. $1.65 \pm 0.41 ; p<0.02$, respectively). A negative correlation between $W C$ and adiponectin level $(R=-0.6275 ; p<0.01)$ and a positive correlation between WC and insulin concentration $(R=0.5122 ; p<0.05)$ as well as with HOMA-IR $(R=0.5228 ; p<0.02)$ were found in group A. Negative correlations between BMI and ghrelin level $(R=-0.7052 ; p<0.05)$, WHR and adiponectin level $(R=-0.6912 ; p<0.05)$ and WHR and leptin level $(R=-0.6728 ; p<0.05)$ were observed in group B.

Conclusions: Insulin resistance and leptin may be important pathogenic factors in hypertensive patients with severe obesity. Indices of abdominal obesity (WC, WHR) correlate better than BMI with HOMA-IR, insulin, adiponectin and leptin serum levels in hypertensive obese patients.

Key words: insulin resistance, obesity, adipokines, ghrelin, hypertension.

\section{Introduction}

Obesity often coexists with hypertension and a linear relationship between blood pressure values and weight was observed [1-3]. Hyper-

\author{
Corresponding author: \\ Mariusz Stępień MD, PhD \\ Department of Nephrology, \\ Hypertension \\ and Family Medicine \\ WAM University Hospital \\ 113 Żeromskiego \\ 90-549 Lodz, Poland \\ Phone: +48426393772 \\ Fax: +48426393782 \\ E-mail: stepm@op.pl
}


tension increases the risk of cardiovascular events such as myocardial infarction, stroke and heart failure in obese patients $[3,4]$.

Body mass index (BMI), waist-to-hip ratio (WHR) and waist circumference (WC) are the classic obesity parameters. Based on BMI values, obesity is classified into three grades: I (BMI 30-34.9 kg/m²), II (BMI $\left.35-39.9 \mathrm{~kg} / \mathrm{m}^{2}\right)$ and III $\left(\mathrm{BMI} \geq 40 \mathrm{~kg} / \mathrm{m}^{2}\right)$. Abdominal obesity, which is described by WHR and WC, has been shown to be more strongly associated with the risk of cardiovascular events than $\mathrm{BMI}[3,5]$.

Pathogenic mechanisms responsible for the coexistence of hypertension and obesity have not been completely explained yet. Increased sympathetic nervous system activity is postulated as one of the most important factors [3]. Some authors also indicate hormonal and adipokine activity, which may play a role in the pathogenesis of both diseases [3, 6-8].

The importance of insulin resistance in the pathogenesis of hypertension is well established $[6,9]$. It has already been shown that obesity leads to the development of insulin resistance and consequently to hyperinsulinemia. Clinical trials (including the San Antonio Heart Study) confirmed hyperinsulinemia as an important risk factor for the development of hypertension [7, 10]. A positive correlation between serum insulin concentrations and blood pressure was observed both in patients with hypertension and in normotensive subjects $[7,11,12]$.

Ghrelin is a peptide hormone secreted by the stomach and duodenum and is involved in shortterm regulation of appetite $[4,6,13,14]$. Ghrelin level in blood rises during fasting and just before a meal and decreases after food intake [13]. It was also observed that ghrelin reduces sympathetic activity $[8,13]$.

Leptin is an adipokine with complex and multidirectional action, which is secreted mainly by adipose tissue [1, 2, 4, 7, 14-17]. This polypeptide informs the brain about body energy reserves, suppresses appetite and modulates energy consumption $[1,2,16]$. Serum leptin concentration is directly related to the content of adipose tissue $[1,2,4]$. Leptin serum level increases in the postprandial period and decreases during starvation $[2,6,16]$. Moreover, leptin affects lipid metabolism, regulates food intake, modulates taste perception and the feeling of satisfaction after consumption, stimulates the sympathetic nervous system and regulates the metabolism of insulin, glucose and triglycerides [1-4, 6, 14, 16].

Adiponectin is a protein synthesized only by adipocytes [2, 6, 7, 16]. It affects regulation of energy metabolism of the body $[2,8,9,16,18]$. Adiponectin has multidirectional biological action. It inhibits hepatic gluconeogenesis, reduces hepatic glucose output and decreases the level of free fatty acids as a result of their oxidation $[9,18,19]$. Moreover, it was shown that this adipokine has complex anti-atherogenic and anti-inflammatory activity $[8,20]$. Unlike other adipokines, plasma concentration of adiponectin is inversely correlated with body mass $[6,16,19]$.

On the basis of prior animals studies, it was suggested that resistin - a polypeptide produced by adipose tissue - might play an important role in the pathogenesis of insulin resistance $[6,9]$. However, other authors did not confirm this finding in humans $[8,20]$. Hence the role of resistin in the pathogenesis of insulin resistance remains controversial.

However, the role of adipokines and hormones in the pathogenesis of both hypertension and obesity in coexistence has not been clearly explained yet. Therefore the aim of our preliminary study was to compare cytokine and hormone (insulin, ghrelin) serum levels as well as insulin resistance (assessed by HOMA-IR) between hypertensive patients both with simple (class I) and severe (class II+III) obesity and also normotensive obese (class I) subjects.

\section{Material and methods}

Thirty-eight out-clinic obese (BMI $\left.\geq 30 \mathrm{~kg} / \mathrm{m}^{2}\right)$ patients of both sexes (11 males, 27 females), aged $51.9 \pm 13.9$ years, were enrolled in the study. Patients were consecutively recruited to the study between the $15^{\text {th }}$ of May and the $2^{\text {nd }}$ of July 2009.

Patients with diabetes, psychiatric disorders, pregnancy, cancer, stroke, severe hepatic or renal disease and acute cardiovascular events or with a history of abdominal surgery, which could have an impact on abdominal fat distribution, were excluded from the study.

All the subjects, after taking the medical history, had their WC and hip circumferences (HC) measured to calculate WHR. Based on BMI values participants were divided into the following 3 groups: A - hypertensive patients with simple (class I) obesity (BMI 30-34.9 kg/m², $n=21$ ), B - hypertensive patients with severe (class II and III) obesity (BMI $\geq 35 \mathrm{~kg} / \mathrm{m}^{2}, n=10$ ) and C - normotensive patients with simple (class I) obesity (BMI $30-34.9 \mathrm{~kg} / \mathrm{m}^{2}, n=7$ ).

Serum glucose concentrations were estimated by glucose hexokinase enzymatic assay (Olympus Beckman Coulter, Switzerland) and total levels of ghrelin, adiponectin, leptin, resistin and insulin were measured using ELISA (EMD Merck Millipore Corp., Germany) in fasting venous blood samples $(8 \mathrm{ml})$ collected from the patients. Insulin resistance was estimated by using the homeostasis model assessment (HOMA-IR) index, which was calculated according to the following formula: (fasting insulinemia $[\mu \mathrm{U} / \mathrm{ml}] \times$ fasting glucose $[\mathrm{mmol} / \mathrm{l}]) / 22.5$ [20]. HOMA-IR values higher than 2.5 were considered as significant for insulin resistance. 
The study protocol was approved by the local Bioethics Committee and informed consent was obtained from all the patients.

\section{Statistical analysis}

Statistical analysis was performed using the statistical software statistica PL 7.1 and $p$ values $<0.05$ were considered as statistically significant.

Fisher's exact test was applied to compare clinical data from Table I. The Shapiro-Wilk test was used to verify whether variable distribution was normal. An ANOVA test (applied when the distribution of the variable in all compared groups was normal) or nonparametric ANOVA Kruskal-Wallis test (applied when the distribution of the variable was not normal in at least one of the compared groups) was used to compare the data in every group.

Patients' demographic and clinical data, mean WC, BMI, WHR and HOMA-IR values, mean serum levels of glucose and insulin, as well as mean serum

Table I. Characteristics of study population

\begin{tabular}{|c|c|c|c|}
\hline \multirow[t]{2}{*}{ Parameter } & \multicolumn{3}{|c|}{ Study groups, $n(\%)$} \\
\hline & $\mathrm{A}(n=21)$ & $\mathrm{B}(n=10)$ & $C(n=7)$ \\
\hline Age [years] & $52.52 \pm 14.86$ & $54.30 \pm 12.09$ & $46.57 \pm 13.58$ \\
\hline Females & 15 (71.4\%) & $8(80 \%)$ & $4(57.1 \%)$ \\
\hline Stable angina & $2(9.52 \%)$ & $3(30 \%)$ & $1(14.3 \%)$ \\
\hline $\begin{array}{l}\text { Myocardial } \\
\text { infarct }\end{array}$ & $4(19.0 \%)$ & - & $1(14.3 \%)$ \\
\hline Cardiac failure & $6(28.6 \%)$ & $6(60 \%)$ & - \\
\hline IGT/IFG & $1(4.76 \%)$ & $2(20 \%)$ & - \\
\hline $\begin{array}{l}\text { Hyperuricemia/ } \\
\text { gout }\end{array}$ & / 4 (19.0\%) & $3(30 \%)$ & - \\
\hline $\begin{array}{l}\text { Hypercholeste- } \\
\text { rolemia }\end{array}$ & $-6(28.6 \%)$ & $1(10 \%)$ & $2(28.6 \%)$ \\
\hline $\begin{array}{l}\text { Hypertriglyce- } \\
\text { ridemia }\end{array}$ & $5(23.8 \%)$ & $2(20 \%)$ & $1(14.3 \%)$ \\
\hline $\begin{array}{l}\text { Combined } \\
\text { hyperlipidemia }\end{array}$ & $5(23.8 \%)$ & $3(30 \%)$ & $2(28.6 \%)$ \\
\hline Hypothyroidism & n 1 (4.76\%) & $1(10 \%)$ & - \\
\hline Diuretics & $14(66.7 \%)$ & $7(70 \%)$ & $2(28.6 \%)$ \\
\hline ACE inhibitors & $9(42.9 \%)$ & $2(20 \%)$ & $2(28.6 \%)$ \\
\hline Sartans & $6(28.6 \%)$ & $3(30 \%)$ & - \\
\hline$\beta$-Blockers & 9 (42.9\%) & $3(30 \%)$ & $1(14.3 \%)$ \\
\hline $\begin{array}{l}\text { Calcium } \\
\text { antagonists }\end{array}$ & 8 (38.1\%) & $3(30 \%)$ & - \\
\hline$\alpha$-Blockers & $1(4.76 \%)$ & - & - \\
\hline Statins & 8 (38.1\%) & $2(20 \%)$ & $2(28.6 \%)$ \\
\hline Fibrates & $5(23.8 \%)$ & $1(10 \%)$ & $2(28.6 \%)$ \\
\hline Sibutramine & $4(19.0 \%)$ & $3(30 \%)$ & - \\
\hline
\end{tabular}

IGT - impaired glucose tolerance, IFG - impaired fasting glucose concentrations of adiponectin, resistin, ghrelin and leptin were compared between groups $A$ and $C$, $A$ and $B$, and B and C. Moreover, Spearman's rank correlation coefficient was used to estimate the correlation between obesity parameters (BMI, WHR, WC) and HOMA-IR, glucose, insulin, ghrelin, resistin, adiponectin and leptin serum levels.

\section{Results}

Characteristics of the study population are presented in Table I. There were no statistically significant differences of demographic and clinical data between patients from each group (Table I).

Patients in group $B$ had a statistically significantly higher mean $\mathrm{BMI}$ value when compared with both groups $A$ and $C\left(38.51 \pm 2.96 \mathrm{~kg} / \mathrm{m}^{2}\right.$ vs. 32.53 $\pm 1.71 \mathrm{~kg} / \mathrm{m}^{2} ; p<0.00001$ and $38.51 \pm 2.96 \mathrm{~kg} / \mathrm{m}^{2} \mathrm{vs}$. $32.49 \pm 2.18 \mathrm{~kg} / \mathrm{m}^{2} ; p<0.003$, respectively) and they also had a higher mean WC value when compared to group A (113.30 $\pm 10.09 \mathrm{~cm}$ vs. $102.90 \pm 8.02 \mathrm{~cm}$; $p<0.05)$ (Table II). Mean values of WHR were comparable in all groups of patients. Leptin level and HOMA-IR were significantly higher in group B compared to group C $(9.74 \pm 3.88 \mathrm{ng} / \mathrm{ml}$ vs. 4.53 $\pm 3.00 \mathrm{ng} / \mathrm{ml} ; p<0.02$ and $3.30 \pm 1.59$ vs. $1.65 \pm 0.41$; $p<0.02$; respectively) (Table II).

A negative correlation between WC and adiponectin level $(R=-0.6275 ; p<0.01)$ and a positive correlation between WC and insulin concentration $(R=0.5122 ; p<0.05)$ as well as with HOMA-IR $(R=0.5228 ; p<0.02)$ were found in group $A$

Table II. Results obtained in patient groups

\begin{tabular}{|c|c|c|c|}
\hline \multirow{2}{*}{$\begin{array}{l}\text { Assessed } \\
\text { feature } \\
\text { or parameter }\end{array}$} & \multicolumn{3}{|c|}{ Study groups, mean \pm SD } \\
\hline & $\mathrm{A}(n=21)$ & $\mathrm{B}(n=10)$ & $C(n=7)$ \\
\hline $\mathrm{BMI}\left[\mathrm{kg} / \mathrm{m}^{2}\right]$ & $32.53 \pm 1.71$ & $38.51 \pm 2.96^{a, b}$ & $32.49 \pm 2.18$ \\
\hline $\mathrm{WC}[\mathrm{cm}]$ & $102.90 \pm 8.02^{*}$ & $113.30 \pm 10.09 c$ & $103.14 \pm 11.29$ \\
\hline WHR & $0.92 \pm 0.07^{*}$ & $0.91 \pm 0.09$ & $0.90 \pm 0.05$ \\
\hline $\begin{array}{l}\text { Adiponectin } \\
{[\mathrm{ng} / \mathrm{ml}]}\end{array}$ & $18.18 \pm 11.93$ & $20.61 \pm 10.26$ & $17.81 \pm 7.20$ \\
\hline $\begin{array}{l}\text { Resistin } \\
{[\mathrm{ng} / \mathrm{ml}]}\end{array}$ & $0.94 \pm 0.46$ & $1.17 \pm 0.43$ & $1.02 \pm 0.50$ \\
\hline $\begin{array}{l}\text { Ghrelin } \\
{[\mathrm{pg} / \mathrm{ml}]}\end{array}$ & $\begin{array}{l}1239.10 \\
\pm 325.98\end{array}$ & $\begin{array}{l}1096.50 \\
\pm 154.17\end{array}$ & $\begin{array}{l}1368.90 \\
\pm 256.45\end{array}$ \\
\hline $\begin{array}{l}\text { Leptin } \\
{[\mathrm{ng} / \mathrm{ml}]}\end{array}$ & $7.32 \pm 4.20$ & $9.74 \pm 3.88^{d}$ & $4.53 \pm 3.00$ \\
\hline $\begin{array}{l}\text { Glucose } \\
{[\mathrm{mmol} / \mathrm{l}]}\end{array}$ & $5.59 \pm 0.48$ & $5.95 \pm 0.78$ & $5.37 \pm 0.65$ \\
\hline $\begin{array}{l}\text { Insulin } \\
{[\mu \mathrm{U} / \mathrm{ml}]}\end{array}$ & $9.83 \pm 5.02$ & $12.73 \pm 6.31$ & $6.88 \pm 1.40$ \\
\hline HOMA-IR & $2.47 \pm 1.37$ & $3.30 \pm 1.59 \mathrm{e}$ & $1.65 \pm 0.41$ \\
\hline
\end{tabular}


Table III. Correlations between compared parameters in group A

\begin{tabular}{|c|c|c|}
\hline Parameters & $R$ & Value of $p$ \\
\hline BMI \& adiponectin & -0.1116 & NS \\
\hline BMI \& resistin & 0.2376 & NS \\
\hline BMI \& ghrelin & 0.2729 & NS \\
\hline BMI \& leptin & 0.0320 & NS \\
\hline BMI \& glucose & 0.2302 & NS \\
\hline BMI \& insulin & 0.3107 & NS \\
\hline BMI \& HOMA-IR & 0.3290 & NS \\
\hline WC \& adiponectin & -0.6275 & $<0.01$ \\
\hline WC \& resistin & 0.2433 & NS \\
\hline WC \& ghrelin & 0.0798 & NS \\
\hline WC \& leptin & -0.1552 & NS \\
\hline WC \& glucose & 0.1729 & NS \\
\hline WC \& insulin & 0.5122 & $<0.05$ \\
\hline WC \& HOMA-IR & 0.5228 & $<0.02$ \\
\hline WHR \& adiponectin & -0.3946 & NS \\
\hline WHR \& resistin & -0.0182 & NS \\
\hline WHR \& ghrelin & 0.0448 & NS \\
\hline WHR \& leptin & -0.3642 & NS \\
\hline WHR \& glucose & 0.0657 & NS \\
\hline WHR \& insulin & 0.2329 & NS \\
\hline WHR \& HOMA-IR & 0.2329 & NS \\
\hline
\end{tabular}

NS - not significant

(Table III). Negative correlations between $\mathrm{BMI}$ and ghrelin level $(R=-0.7052 ; p<0.05)$, WHR and adiponectin level $(R=-0.6912 ; p<0.05)$, and WHR and leptin level $(R=-0.6728 ; p<0.05)$ were observed in group $B$ (Table IV). We did not observe any statistically significant correlation between compared parameters in group C (Table V).

\section{Discussion}

The results of our preliminary study indicate the important role of leptin in the pathogenesis of hypertension and severe obesity. Leptin serum level in group B was also higher than in hypertensive patients with simply obesity, but the difference did not reach statistical significance. Therefore we suggest that the highest leptin concentration in group $B$ might be associated with both hypertension and degree of obesity. Our findings are in accordance with the results of other studies showing elevated serum leptin levels in obese patients, both hypertensive and normotensive [6, 10-12, 17]. Higher leptin plasma concentrations were also reported in patients with essential hypertension [10-12]. Leptin produced by adipocytes is considered to be a sig-
Table IV. Correlations between compared parameters in group $\mathrm{B}$

\begin{tabular}{|lll|}
\hline Parameters & $R$ & Value of $p$ \\
\hline BMI \& adiponectin & 0.3161 & NS \\
\hline BMI \& resistin & -0.1216 & NS \\
\hline BMI \& ghrelin & -0.7052 & $<0.05$ \\
\hline BMI \& leptin & 0.0243 & NS \\
\hline BMI \& glucose & -0.0851 & NS \\
\hline BMI \& insulin & 0.0547 & NS \\
\hline BMI \& HOMA-IR & -0.0182 & NS \\
\hline WC \& adiponectin & -0.2195 & NS \\
\hline WC \& resistin & -0.2500 & NS \\
\hline WC \& ghrelin & -0.3598 & NS \\
\hline WC \& leptin & -0.3537 & NS \\
\hline WC \& glucose & 0.1341 & NS \\
\hline WC \& insulin & 0.2866 & NS \\
\hline WC \& HOMA-IR & 0.3171 & NS \\
\hline WHR \& adiponectin & -0.6912 & $<0.05$ \\
\hline WHR \& resistin & -0.2814 & NS \\
\hline WHR \& ghrelin & -0.0122 & NS \\
\hline WHR \& leptin & -0.6728 & 0.05 \\
\hline WHR \& glucose & 0.1468 & NS \\
\hline WHR \& insulin & 0.0734 & NS \\
\hline WHR \& HOMA-IR & 0.1223 & NS \\
\hline
\end{tabular}

NS - not significant

nificant factor linking obesity with sympathetic activation $[1,12]$.

It has been shown that insulin resistance and hyperinsulinemia are important factors participating in the pathogenesis of hypertension in patients with obesity $[6,7,9]$. Obesity is associated mainly with insulin receptor resistance, resulting from the impairment of insulin binding to tissue receptors, especially in adipose tissue and muscles [2, 4, 20]. Hyperinsulinemia, like hyperleptinemia, contributes to activation of the sympathetic nervous system and subsequently to the increase in blood pressure [11, $12,15,17]$. We found significantly higher HOMA-IR in hypertensive patients with severe obesity than in normotensive obese subjects. This difference could result from both hypertension and the higher degree of obesity in this group. Based on the results of our study we suggest that also visceral obesity should be taken into consideration, because WC was higher in group B than in group C. In previously published data we observed higher WC and leptin serum levels in obese insulin-resistant patients in comparison to obese insulin-sensitive subjects independently of BMI [21]. Thus our obser- 
vations confirm the importance of insulin resistance in the pathogenesis of hypertension and obesity.

We did not find any significant differences in serum concentrations of other adipokines or ghrelin between the study groups. This could result from the small number of patients included in the study, especially in group $C$.

Abdominal obesity is often associated with hypertension and the risk of cardiovascular events. Indices of abdominal obesity such as WC and WHR are postulated to be better predictors of cardiovascular risk and mortality than $\mathrm{BMI}[3,5,7]$. In our study we noted higher WC in hypertensive patients with severe obesity than in hypertensive patients with simple obesity. The results of our study also revealed that indicators of abdominal obesity, such as WC and WHR, correlated better than BMI with HOMA-IR and serum concentrations of insulin, leptin and adiponectin in obese patients with hypertension. Previously published data showed a strong association between visceral obesity and insulin resistance as well as with serum level of insulin [7]. The negative correlations observed in our study between indicators of abdominal obesity and serum concentration of adiponectin are in agreement with other reports showing an inverse correlation between adiponectin and body fat mass [2, 7, 16, 18, 19].

We observed a negative correlation between WHR and serum concentration of leptin in hypertensive patients with severe obesity, while the leptin serum level was significantly higher in this group in comparison to normotensive patients with simple obesity. Based on data obtained from our study we were unable to explain this observation. Other authors reported a positive correlation between leptin blood concentration and WHR [22]. However, Corica et al. found a negative correlation between leptin plasma levels and WHR in obese patients, which is consistent with our findings [23].

In contrast to some previously published data, we did not find any statistically significant positive correlation between leptin serum concentration and BMI $[6,19,23,24]$. However, Bednarek-Tupikowska et al. as well as Minocci et al. did not find any correlation between leptin concentration in blood and $\mathrm{BMI}$, which is in accordance with the results of our study $[21,25]$.

Previous studies have shown a negative correlation between ghrelin level in blood and BMI and WC $[26,27]$. Lower levels of serum ghrelin were observed in obese normotensive women, while higher levels were reported in obese women with hypertension [28, 29]. Nevertheless, based on the results obtained from our study, obesity could seem to be a stronger determinant of ghrelin secretion than hypertension, since ghrelin serum levels were reduced in the patients with $\mathrm{BMI}>35 \mathrm{~kg} / \mathrm{m}^{2}$ regardless of the coexistence of hypertension,
Table V. Correlations between compared parameters in group $C$

\begin{tabular}{|lll|}
\hline Parameters & \multicolumn{1}{c}{$R$} & Value of $p$ \\
\hline BMI \& adiponectin & 0.0000 & NS \\
\hline BMI \& resistin & -0.5714 & NS \\
\hline BMI \& ghrelin & 0.1429 & NS \\
\hline BMI \& leptin & 0.2143 & NS \\
\hline BMI \& glucose & 0.4286 & NS \\
\hline BMI \& insulin & 0.4286 & NS \\
\hline BMI \& HOMA-IR & 0.5357 & NS \\
\hline WC \& adiponectin & -0.5225 & NS \\
\hline WC \& resistin & -0.5586 & NS \\
\hline WC \& ghrelin & -0.3243 & NS \\
\hline WC \& leptin & 0.1261 & NS \\
\hline WC \& glucose & 0.3964 & NS \\
\hline WC \& insulin & 0.5946 & NS \\
\hline WC \& HOMA-IR & 0.6667 & NS \\
\hline WHR \& adiponectin & -0.5357 & NS \\
\hline WHR \& resistin & -0.3571 & NS \\
\hline WHR \& ghrelin & -0.3214 & NS \\
\hline WHR \& leptin & -0.0357 & NS \\
\hline WHR \& glucose & 0.6071 & NS \\
\hline WHR \& insulin & 0.5357 & NS \\
\hline WHR \& HOMA-IR & 0.7500 & NS \\
\hline
\end{tabular}

NS - not significant

although this difference did not reach statistical significance. A similar association was noted by other authors [8]. Our results confirm the negative correlation between ghrelin and $\mathrm{BMI}$ in hypertensive patients with severe obesity, but we did not observe such a relationship for WC or WHR.

The study has some important limitations. The patient groups were small and therefore some results could not reach or were bordering on statistical significance. Also we could not evaluate sex-dependent differences in both groups because of too few patients, especially in group C. Therefore further detailed studies based on a larger population are needed for a more comprehensive evaluation [28-36].

In conclusion, data obtained from our study indicate that insulin resistance and leptin may be important pathogenic factors in hypertensive patients with severe obesity. Indices of abdominal obesity correlate better than BMI with HOMA-IR and with insulin, adiponectin and leptin serum levels in hypertensive obese patients.

\section{Acknowledgments}

The authors thank Dr. Anna Gluba for help in translating the text of this article. The authors 
declare no conflict of interest with respect to this study.

\section{References}

1. Wofford MR, Hall JE. Pathophysiology and treatment of obesity hypertension. Curr Pharm Des 2004; 10: 3621-37.

2. Havel PJ. Section IV: Lipid modulators of islet function. Update on adipocyte hormones. Regulation of energy balance and carbohydrate/lipid metabolism. Diabetes 2004; 53: S143-51.

3. Diaz ME. Hypertension and obesity. J Hum Hypertension 2002; 16 (Suppl 1): S18-22.

4. Soufi M, Sattler AM, Herzum M, et al. Molecular basis of obesity and the risk for cardiovascular disease. Herz 2006; 31: 200-6.

5. Dalton M, Cameron AJ, Zimmet PZ, et al. Waist circumference, waist-hip ratio and body mass index and their correlation with cardiovascular disease risk factors in Australian adults. J Int Med 2003; 254: 555-63.

6. Meier U, Gressner AM. Endocrine regulation of energy metabolism: review of pathobiochemical and clinical aspects of leptin, ghrelin, adiponectin and resistin. Clin Chem 2004; 50: 1511-25.

7. Sharma AM, Chetty VT. Obesity. Hypertension and insulin resistance. Acta Diabetol 2005; 42: S3-8.

8. Vendrell J, Broch M, Vilarrasa N, et al. Resistin, adiponectin, ghrelin, leptin and proinflammatory cytokines: relationships in obesity. Obesity Res 2004; 12: 962-71.

9. Miner JL. The adipocyte as an endocrine cell. J Animal Sci 2004; 82: 935-41.

10. Haffner S.M. Obesity and the metabolic syndrome: the San Antonio Heart Study. Br J Nutr 2000; 83 (Suppl 1): 67-70.

11. Kotchen TA. Obesity-related hypertension: epidemiology, pathophysiology and clinical management. Am J Hypertens 2010; 23: 1170-8.

12. Kotsis V, Stabouli S, Papakatsika S, et al. Mechanisms of obesity-induced hypertension. Hypertens Res 2010; 33 386-93.

13. Cummings DE, Overduin J. Gastrointestinal regulation of food intake. J Clin Invest 2007; 117: 13-23.

14. Altman J. Weight in the balance. Neuroendocrinology 2002; 76: 131-6.

15. Singh M, Bedi US, Singh PP, et al. Leptin and the clinical cardiovascular risk. Int J Cardiol 2009; 140: 266-71.

16. Trayhurn P, Bing C, Wood IS. Adipose tissue and adipokines - energy regulation from the human perspective. J Nutrition 2006; 136: 1935S-9S.

17. Baráth À, Túri S, Németh I, et al. Different pathomechanisms of essential and obesity-associated hypertension in adolescents. Pediatr Nephrol 2006; 21: 1419-25.

18. Wang ZV, Scherer PE. Adiponectin. Cardiovascular function and hypertension. Hypertension 2008; 51: 8-14.

19. Abdullah AR, Haydar AH, Raigangar VL, et al. Analysis of the relationship of leptin, high-sensitivity C-reactive protein, adiponectin, insulin and uric acid to metabolic syndrome in lean, overweight and obese young females. Metabolic Syndrome and Related Disorders 2008; 7: 17-22.

20. Lee JH, Chan JL, Yiannakouris N, et al. Circulating resistin levels are not associated with obesity or insulin resistance in humans and are not regulated by fasting or leptin administration: cross-sectional and interventional studies in normal, insulin-resistant, and diabetic subjects. J Clin Endocrinol Metab 2003; 88: 4848-56.

21. Stępień M, Rośniak-Bąk K, Paradowski M, et al. Waist circumference, ghrelin and selected adipose tissue-derived adipokines as predictors of insulin resistance in obese patients. Med Sci Monit 2011; 17: PR13-8.

22. Park KG, Park KS, Kim MJ, et al. Relationship between serum adiponectin and leptin concentrations and body fat distribution. Diab Res Clin Pract 2004; 63: 135-42.

23. Corica F, Allegra A, Corsonello A, et al. Relationship between plasma leptin levels and the tumor necrosis factor-alpha system in obese subjects. Int J Obes Rel Metab Disord 1999; 23: 355-60.

24. Bednarek-Tupikowska G, Filus A, Kuliczkowska-Płaksej J, et al. Serum leptin concentrations in pre- and postmenopausal women on sex hormone therapy. Gyn Endocrinol 2006; 22: 207-12.

25. Minocci A, Savia G, Lucantoni R, et al. Leptin plasma concentrations are dependent on body fat distribution in obese patients. Int J Obes 2000; 24: 1139-44.

26. Monti V, Carlson J, Hunt S, et al. Relationship of ghrelin and leptin hormones with body mass index and waist circumference in random sample of adults. J Am Diet Assoc 2006; 106: 822-8.

27. Sondergaard E, Gormsen LC, Nellemann B. Visceral fat mass is a strong predictor of circulating ghrelin levels in premenopausal women. Eur J Endocrinol 2009; 160: 375-9.

28. Barylski M, Małyszko J, Rysz J, Myśliwiec M, Banach M. Lipids, blood pressure, kidney - what was new in 2011? Arch Med Sci 2011; 7: 1055-66.

29. Öner-Iyiodogan Y, Koçak H, Gürdöl F, et al. Circulating ghrelin levels in obese women: a possible association with hypertension. Scand J Clin Lab Invest 2007; 67: 568-76.

30. Katsiki N, Mikhailidis DP, Banach M. Effects of statin treatment on endothelial function, oxidative stress and inflammation in patients with arterial hypertension and normal cholesterol levels. J Hypertens 2011; 29: 2493-4.

31. Kędziora-Kornatowska K, Czuczejko J, Motyl J, et al. Effects of coenzyme Q10 supplementation on activities of selected antioxidative enzymes and lipid peroxidation in hypertensive patients treated with indapamide. A pilot study. Arch Med Sci 2010; 6: 513-8.

32. Banach M, Goch JH, Ugurlucan M, Rysz J, Mikhailidis DP. Obesity and postoperative atrial fibrillation. Is there no connection? Comment on: Wanahita et al. "Atrial fibrillation and obesity - results of a meta-analysis". Am Heart J 2008; 156: e5.

33. Mizia-Stec K, Haberka M, Mizia M, et al. N-3 Polyunsaturated fatty acid therapy improves endothelial function and affects adiponectin and resistin balance in the first month after myocardial infarction. Arch Med Sci 2011; 7: 788-95.

34. Tahira K, Ueno T, Fukuda N, et al. Obesity alters the expression profile of clock genes in peripheral blood mononuclear cells. Preliminary results. Arch Med Sci 2011; 7: 933-40.

35. Katsiki N, Banach M. Statins and the risk of diabetes: the debate. Arch Intern Med 2012; 172: 895-6.

36. Banach M, Aronow WS. Should we have any doubts about hypertension therapy in elderly patients? ACCF/AHA 2011 expert consensus document on hypertension in the elderly. Pol Arch Med Wewn 2011; 121: 253-8. 